\title{
Mineração e dependência no quadrilátero ferrífero.
}

Tádzio Peters Coelho

\section{Resumo}

Pretendemos com esse trabalho evidenciar as relações de classe entre as Mineradoras e a sociedade civil local, por meio principalmente da Teoria da Dependência. Tentamos refletir sobre os efeitos da atividade minério-exportadora nas populações locais da região mineradora e as maneiras de manutenção dessa ordem social. Em alguns momentos, focamos nossa análise especificamente na cidade de Raposos e na cidade de Caeté (região metropolitana de Belo Horizonte) onde mitiga a licitação do Projeto Apolo da Vale S.A. Partimos da hipótese de que são inúmeros os danos causados pela mineração à sociedade civil local, principalmente a longo e médio prazo. A população local e as classes populares não mobilizam um discurso contra-hegemônico, ou mesmo questionador, de ampla aceitação na sociedade civil local porque o discurso do progresso e desenvolvimento e a dependência econômica da região frente à mineração desmobilizam os movimentos críticos e contrários às mineradoras. Esta dependência econômica é traduzida em dependência sócio-política.

Palavras-chave: Mineração, dependência, desenvolvimento, Vale.

\begin{abstract}
We intend at this work to show the class relations between miner companies and local civil society, primarily through the Dependency Theory. We try to reflect about the social effects of the ore exports in local populations of the mining regions and the ways of maintaining this social order. Sometimes, we focused our analysis specifically in the city of Caeté where mitigates the Projeto Apolo of Vale SA. Our hypothesis is that there are numerous damage caused by mining to the local civil society. The local population and the working classes do not mobilize a counter-hegemonic discourse, or even questioning, wide accepted in the local community because of the discourse of progress and development and the economic dependency of the region to the mining demobilize the opposite movements to mining.
\end{abstract}

Keywords: mining, dependence, development, Vale. 


\section{Apresentação}

O debate sobre o subdesenvolvimento e a dependência encontrou seu auge em meados do século $\mathrm{XX}$, mas ressurge com toda a força, por isso a necessidade de o aprofundarmos é atualíssima. Intentamos com esse trabalho trazer esta discussão para nível local, onde possamos não só compreender, mas nos inserir no debate como força transformadora.

É necessário interrogar o tipo de desenvolvimento que vem sendo levado a cabo na região do Quadrilátero Ferrífero e, em nível mais amplo, no país, com a crescente especialização na exportação de matérias-primas. A região por nós estudada, apesar de incontáveis riquezas produzidas ao longo da história, jamais desfrutou de um desenvolvimento autônomo e justo, padecendo pela concentração de renda, marginalização social, desemprego e subordinação política. Esta pesquisa vem, esperamos, para questionar a manutenção de tais características. É necessário esclarecer o que compreendemos por desenvolvimento. Para nós, desenvolvimento social e econômico vai para além do simples crescimento econômico, o desenvolvimento deve ser entendido como forma de se combater a miséria e a pobreza e diminuição da desigualdade social. O desenvolvimento genuíno se dá quando os países periféricos realizam políticas que vão no caminho contrário da dependência. Mesmo o Brasil se tornando a sexta maior economia do mundo persistiram a concentração da renda e a miséria, não superamos o subdesenvolvimento, o que por sua vez:

repõe duas questões decisivas: (1) de um lado, ela reitera que o processo de desenvolvimento não se confunde com o simples crescimento econômico, mesmo quando ele é expressivo e prolongado; (2) de outro lado, ela cobra a necessidade de atualização de um programa para o desenvolvimento à luz das realidades contemporâneas. (PAULA, 2009, p. 114)

Igualar desenvolvimento ao montante de dinheiro investido pelas grandes mineradoras é um ato confuso além de pernicioso para a profunda compreensão da relação entre mineração e desenvolvimento. 
Nossa primeira hipótese é de que a dependência econômica, social e política da região frente a mineração é o principal empecilho para a formulação de projetos alternativos. A mineração traz inúmeros males, tem um desenvolvimento limitado e as populações aceitam-na porque dependem dela para conseguirem emprego e para atender às suas primeiras necessidades. É este fato primário que constrange a população local a aceitar os desígnios da mineração e seus inerentes males.

A segunda hipótese é de que são inúmeros os danos causados pela mineração à sociedade civil local, principalmente a longo e médio prazo, quando a mineração mostra seu caráter transitório (como bem definiu Artur Bernardes: "o minério só dá uma safra") e depredatório do homem e da natureza. São pouquíssimos empregos diretos criados, que geralmente exigem mão de obra altamente qualificada inexistente nas regiões mineradoras, aumentando a concentração de renda e, assim, a desigualdade social. Numa comparação entre ônus e bônus, no que podemos chamar de dicotomia da dependência, o ônus fica principalmente com a população local. $\mathrm{O}$ grande beneficiado com a mineração são as mineradoras em detrimento da população local. Porém, o que não se tem claro é sobre o que é esse ônus minerador, que envolve não só supostos problemas ambientais, mas ainda efeitos que muitas vezes não são identificados como consequências da mineração. Assim, queremos saber como se dá esse processo. Para isso teremos que compreender como se dá a acumulação de capital nesta atividade econômica.

\section{Introdução}

A região de Minas Gerais é historicamente conhecida por sua indústria extrativa relacionada à mineração. A relação da região com esses recursos naturais está ligada à exportação desde fins do século XVII, quando encontrou-se por meio das bandeiras as primeiras minas de ouro da colônia brasileira na região de Minas Gerais. Um gigantesco fluxo migratório instalou-se em direção à região. A população brasileira pulou de 100 mil em 1600, para 300 mil em 1700, e 3,25 milhões em 1800 (FURTADO, 2000, p. 111). O ouro preto - que era o ouro de aluvião que se descolava das encostas das montanhas indo parar nos leitos dos rios - era encontrado sob os pés dos exploradores. Tanta era a abundância de ouro que em dias de chuva na antiga Ouro Preto, muitos iam às sinuosas 
ladeiras da cidade garimpar o ouro. Esse primeiro ciclo econômico das Minas termina em fins do século XVIII. Ouro Preto nos ensina algo decisivo para os dias de hoje: que a simples descoberta de um valioso recurso natural não é sinônimo de desenvolvimento sócio-econômico local:

\begin{abstract}
"Chega-se em fins do século XVIII a um momento em que já se tinham esgotado praticamente todos os depósitos superficiais em toda a vasta área em que ocorreram. A mineração sofre então seu colapso final. Nada se acumulara na fase mais próspera para fazer frente à eventualidade. Os recursos necessários para restaurar a mineração, reorganizá-la sobre novas bases que a situação impunha, tinham se volatizado, através do oneroso sistema fiscal vigente, no fausto da corte portuguesa e na sua dispendiosa e ineficiente administração (...) A ignorância, a rotina, a incapacidade de organização nessa sociedade caótica que se instalara nas minas, e cuja constituição não fora condicionada por outro critério que dar quintos a um rei esbanjador e à sua corte de parasitos, e no resto satisfazer o apetite imoderado de aventureiros, davam-se as mãos para completar o desastre" (PRADO Jr, 1984, p.62).
\end{abstract}

A mineração rendera poucos empregos, era baseada no trabalho escravo, não desenvolveu o mercado interno, já que era uma atividade essencialmente exportadora, e deixou como herança a destruição do homem e da natureza.

O ouro não engendrou segmentos produtivos in loco, pois muito se gastava na importação de gêneros de subsistência e quase nada se produzia dentro das Minas, não ocorrendo, também, a retenção do excedente produzido. A compulsoriedade do trabalho tornava desnecessário o aperfeiçoamento técnico e a aquisição de máquinas, sendo os investimentos revertidos na compra de escravos. Os mecanismos do sistema colonial - o fisco, a tributação sobre escravos, o sistema monetário implantado, as importações em regime de exclusivo comércio - fizeram com que a maior parte dessa riqueza se esvaísse. Segundo Furtado (2000, p. 111), no complexo econômico mineratório, "o desenvolvimento endógeno - isto é, com base em seu próprio mercado - foi praticamente nulo". Isso se deveu à incapacidade técnica dos nativos para iniciar atividades manufatureiras. Imbricados a estes fatores internos estão as limitações externas, essenciais para explicar o subdesenvolvimento da região. Houveram os impedimentos impostos pela metrópole que proibiu a colônia de produzir e desenvolver sua própria indústria manufatureira. A limitação do desenvolvimento da região de Minas Gerais tem como principais características a exploração e a dominação a qual sua as classes populares foram 
submetidas. Isso é consequência da relação de dependência entre a colônia e a metrópole, na qual, aliada à classe dominante nativa, a classe estrangeira explora o trabalho e os recursos naturais locais.

Antes de encampar uma discussão sobre a dependência na região do quadrilátero ferrífero é necessário expôr, de forma introdutória, os antecedentes intelectuais da Teoria da Dependência na América Latina. Para nós é evidente a influência dos estudos da Cepal (Comissão Econômica para América Latina e Caribe) das décadas de 1950 e 1960 na formulação da Teoria da Dependência, o que exige uma abordagem sobre a teoria cepalina, mesmo que de forma superficial.

\section{A Cepal}

A Cepal é uma instituição das Nações Unidas criada para analisar as condições econômicas e sociais do subcontinente latino-americano e Caribe, dessa forma, propondo políticas que lidem com os problemas decorrentes do subdesenvolvimento. É detentora de um dos pensamentos mais originais já criados nos trópicos e parte da ideia de que é necessário uma compreensão própria e original para empreender o desenvolvimento periférico (países subdesenvolvidos), que não é do mesmo tipo que o desenvolvimento realizado pelos países do capitalismo central (países desenvolvidos). Assim, contraria os estudos prévios a sua criação, como o de Rostow (1962), segundo os quais o subdesenvolvimento da periferia seria vencido pelos mesmos caminhos trilhados pelos países centrais. A Cepal foi criada em 1949 e tem como principais representantes os intelectuais Raúl Prébish, Celso Furtado, Maria da Conceição Tavares, Oswaldo Sunkel, Aníbal Pinto, Fernando Fajnzylber, dentre outros.

Segundo Bielschowsky (2000, p.17), sua principal inovação é metodológica. Combinando a análise histórica com o método estruturalista, a CEPAL tenta buscar soluções para subdesenvolvimento latino-americano.

Sua metodologia manteve alguns princípios básicos durante toda a segunda metade do século XX. O que mudou foi o contexto histórico e os desafios dele decorrentes. Por isso, o enfoque histórico-estruturalista cepalino tem como grande trunfo a maleabilidade de sua interpretação não padecendo de rígidos marcos que o petrificariam no passado, ao 
mesmo tempo em que uma parte relevante dos estudos da Cepal são uma tentativa de crítica ao seu próprio método.

As ações em prol do desenvolvimento seriam tomadas pela via estatal as quais teriam um planejamento a longo prazo. Além da intervenção estatal, são fundamentais no pensamento cepalino a inserção das economias periféricas na economia mundial e as limitações internas do subedesenvolvimento.

\section{A Teoria da Dependência}

É importante destacar a forte influência que os estudos cepalinos exerceram sobre os teóricos da dependência. Podemos até mesmo dizer que a ideia de dependência já se encontrava embrionária dentro do pensamento da Cepal. A Teoria da Dependência pode ser dividida em duas vertentes principais (BRESSER-PEREIRA, 2005, p. 220):

1-) A vertente da Dependência Associada, da qual faz parte Fernando Henrique Cardoso e Enzo Faletto com o já-clássico trabalho "Dependência e Desenvolvimento na América Latina" (1969). Muito basicamente, e até mesmo de forma simplista, esta corrente teórica constata a impossibilidade do desenvolvimento nacional ser liderado pelas burguesias dependentes, o que os leva a conclusão decorrente da primeira afirmação de que os países dependentes devem se associar ao sistema dominante de forma que possam obter algumas benesses dessa relação. Assim, a corrente da Dependência Associada compartilha da visão da corrente marxista da dependência de que a burguesia local está impossibilitada de realizar o desenvolvimento nacional, até porque uma das condições para o desenvolvimento seria a criação de uma poupança interna, e a burguesia local está envolvida no consumo conspícuo, imitando o padrão de vida dos países centrais. Essa interpretação da dependência se localiza em um contexto histórico onde a industrialização latino-americana dos anos 50s e 60s obteve fortes investimentos estrangeiros, o que por si mostrava, dentro da visão da dependência associada, as possibilidades de desenvolvimento trazidas por esta relação.

2-) A outra interpretação da dependência é a marxista, ou a que podemos chamar de teoria da superexploração do trabalho ou Teoria Marxista da Dependência. O que a 
diferencia da Teoria da Dependência Associada não é o fato de ser um estudo de interpretação marxista. Ambos foram intensamente influenciados pelo método marxista, assim, não sendo este um elemento de diferenciação. Na vertente da superexploração do trabalho, as classes altas dos países periféricos não realizam uma exploração do trabalho, mas uma superexploração do trabalho, visto que dividem os lucros com as classes estrangeiras. O locus de consumo está predominantemente localizado nos países centrais, possibilitando uma superexploração do trabalhador, já que não será ele o sujeito do consumo:

\begin{abstract}
"A produção latino-americana não depende da capacidade interna de consumo. Há uma separação entre a produção e a circulação das mercadorias. Aqui aparece de maneira específica a contradição inerente à produção capitalista, acaba com o trabalhador vendedor e comprador. Em conseqüência a tendência do sistema será de explorar ao máximo a força de trabalho do operário, sem se preocupar em criar as condições para que este a reponha, sempre e quando se possa suprir mediante a incorporação de novos braços ao processo produtivo. Acentua até os limites as contradições dessas relações de trabalho" (MARINI, 1985).
\end{abstract}

As classes altas locais não direcionam grandes investimentos na criação de tecnologia e progresso da ciência, que são monopolizados pelas classes altas dos países centrais, o que possibilitaria auferir sobre o trabalhador a taxa de mais-valia relativa por meio do aumento da produtividade. Assim, retiram do trabalhador a mais-valia absoluta, por meio do rebaixamento dos salários e da intensificação do trabalho através do aumento da jornada de trabalho. Rebaixam os salários a níveis em que coloque em risco a sobrevivência do próprio trabalhador. Isto tem vários efeitos sociais, como a falta de oportunidades de emprego, analfabetismo, subnutrição, repressão policial e violência (MARINI, 2000).

Nos países dependentes o mecanismo econômico básico deriva da relação exportação-importação: ainda que se obtenha no interior da economia, a mais-valia se realiza na esfera do mercado externo mediante a atividade de exportação, e se traduz em ingressos que se aplicam, em sua maior parte, em importações e no consumo luxuoso. A produção interna depende do mercado externo. 


\section{Subdesenvolvimento e Dependência}

Por algum tempo, perdurou nas Ciências Sociais a interpretação evolutiva do desenvolvimento, na qual existiria um linha evolutiva entre subdesenvolvimento e desenvolvimento - hoje subdesenvolvido, amanhã desenvolvido. Assim, a pobreza dos países subdesenvolvidos é resultado, exclusivamente, da incompetência deles próprios, isso é, causada por razões internas. Dentro dessa interpretação, seria necessário que os países subdesenvolvidos sigam os caminhos trilhados pelos países desenvolvidos para também se tornarem desenvolvidos. Nesse ponto, a CEPAL e a Teoria da Dependência concordam que:

A consequência é que a maior parte de nossas teorias não consegue explicar a estrutura e o desenvolvimento do sistema capitalista como um todo e não esclarece a geração simultânea de subdesenvolvimento em algumas de suas partes e de desenvolvimento econômico em outras. (...). Basta, porém, uma pequena familiarização com a história para saber que o subdesenvolvimento não é original nem tradicional, e que nem o passado nem o presente dos países subdesenvolvidos se parecem em qualquer aspecto importante com o passado dos países hoje desenvolvidos. Os países atualmente desenvolvidos nunca foram subdesenvolvidos, embora possam ter sido não-desenvolvidos. (FRANK, 1973, p. 26).

Já a Teoria da Dependência Associada defende a idéia de que é necessário que as economias periféricas se aliem interinamente ao capital externo, de tal forma que se beneficiem de seus investimentos e da transferência de tecnologia. André Gunder Frank critica esta hipótese mostrando que as regiões que hoje são as mais subdesenvolvidas tiveram no passado estreitas ligações com os países desenvolvidos, isso é, realizaram o desenvolvimento do subdesenvolvimento, tornando-se regiões deprimidas nos dias de hoje:

Uma terceira hipótese importante, derivada da estrutura metrópole-satélite, é que as regiões que hoje são as mais subdesenvolvidas e aparentemente feudais são as que no passado tiveram as ligações mais estreitas com a metrópole. São as regiões que foram as maiores exportadoras de produtos primários para a metrópole mundial, e que foram abandonadas pela metrópole quando, por um ou outro motivo, os negócios caíram. Essa hipótese também contradiz a tese geralmente aceita de que a raiz do subdesenvolvimento de uma região é seu isolamento e suas instituições précapitalistas. (FRANK, 1973, p. 35). 
Obviamente, a afirmação de que as regiões subdesenvolvidas hoje foram no passado as mais ligadas ao capitalismo central não é um imperativo, isso é, não é regra que as regiões subalternas ligadas ao capitalismo central enfrentarão o desenvolvimento do subdesenvolvimento. Porém, nos parece claro de que as regiões do nordeste brasileiro (com o ciclo da cana), de Minas Gerais e Norte brasileiro (com o ciclo da borracha) passaram por este processo.

Sendo assim, Bettelheim conclui que:

Esses fatos mostram como seriam mais justificado falar em países de "economia sufocada ou estrangulada" do que em países "subdesenvolvidos". Esses fatos são essenciais à compreensão da tendência ao bloqueamento do desenvolvimento econômico de um grande número de países dependentes. (BETTELHEIM, p. 67).

A TMD entra com uma compreensão dialética da relação entre desenvolvimento e subdesenvolvimento. Para eles, a diferença nessa relação não é quantitativa, e sim qualitativa. Ao invés de compreender o desenvolvimento como uma linha evolutiva, devemos entendê-lo como uma relação entre extremos contraditórios e complementares: os países centrais precisam dos periféricos pela farta mão-de-obra barata e pela transferência de valores; e os periféricos, para empreender o desenvolvimento do subdesenvolvimento, necessitam das divisas e da tecnologia dos países centrais, aprofundando, assim, sua relação de dependência.

Para Marini a relação se resume na seguinte forma:

\footnotetext{
"A dependência é uma relação de subordinação entre nações formalmente independentes, em cujo marco das relações de produção das nações subordinadas são modificadas ou recriadas para assegurar a reprodução da dependência ampliada. O mero fato de que algumas nações industriais produzam bens que as demais não produzem, permite que as primeiras elucidem a lei do valor, isso é, vendam seus produtos a preços superiores a seu valor, configurando um intercâmbio desigual. Isto implica que as nações desfavorecidas devam ceder gratuitamente parte do valor que produzem. A função cumprida pela América Latina no desenvolvimento do capitalismo mundial foi de fornecer bens pecuários aos países industriais, e de contribuir para a formação de um mercado de matérias primas industriais" (MARINI, 1977, p. 41).
}

Porém, é necessário também observar que para a TMD as condições internas dos países dependentes, além das relações entre as classes nacionais e suas ligações com a 
economia mundial, são essenciais para compreendermos a dependência. Assim, procuram se distanciar de uma interpretação que coloque apenas fatores externos como condicionante das sociedades dependentes, destacando a relevância do estudo das condições internas dos países dependentes, sendo esta uma das principais inovações metodológicas da Teoria da Dependência em geral:

La respuesta final no está sin embargo, determinada por esta situación condicionante, sino por las fuerzas internas que componen la sociedad dependiente. Es el carácter de estas fuerzas internas lo que explica su situación sumisa así como su capacidad de enfrentamiento com los impulsos externos que la condicionan (SANTOS, 1978, p. 13).

Na compreensão da TMD, a dependência econômica é uma situação na qual uma economia está condicionada pelo desenvolvimento e expansão de outra. São três os condicionantes histórico-estruturais da dependência: 1-) a perda nos termos de troca, ou seja, a redução dos preços dos produtos exportados pelos países dependentes, visto que, em geral, são primários, em troca de produtos de alto valor agregado; 2-) remessa de excedentes para o centro capitalista, por meio de juros, lucros, amortizações, dividendos e royalties, visto que os países dependentes importam tecnologia dos avançados; 3-) instabilidade dos mercados financeiros internacionais, o que afeta os países periféricos pelas altas taxas de juros no crédito (CARCANHOLO, 2009, p. 254).

Podemos notar a condição de dependência dos países periféricos em relação ao centro do capitalismo, envolvendo a troca de commodities, ou produtos primários, por produtos com alto valor agregado, havendo uma transferência de valores. Mesmo que no caso do Brasil a relação não seja tão simples, já que o país atingiu um certo grau de industrialização, ainda sim o país se insere de forma subalterna na economia mundial. Dos quinze principais produtos exportados pelo Brasil em 2010, dez podem ser considerados commodities. Além do minério ser o principal produto de exportação com 15,3\% das exportações (Fonte: Ministério do Desenvolvimento, Indústria e Comércio Exterior). Segundo o jornal Valor Econômico: "Em 2010, as vendas de cinco commodities - minério de ferro, petróleo em bruto, soja (grão, farelo e óleo), açúcar (bruto e refinado) e complexo carnes - responderam por $43,4 \%$ do valor total exportado pelo Brasil, uma fatia bastante superior aos 27\% de 2004" (13.01.2011, pg. A3). Os dados têm sérias implicações 
concretas, como a capacidade de pressão do capital estrangeiro sobre nossa política econômica, a dependência econômica, tecnológica e política frente ao estrangeiro. Em estudo realizado pela Fundação João Pinheiro em junho de 2011, sobre a indústria em Minas Gerais, mostrou-se que "os fatores contribuintes para a desaceleração do crescimento em Minas Gerais são os mesmos apontados no plano nacional: a retirada dos estímulos fiscais para o fortalecimento da demanda agregada ao longo do segundo semestre do ano passado; as medidas de restrição ao crédito bancário dos últimos meses de 2010; a contínua elevação da taxa básica de juros pelo Banco Central; e o arrefecimento do ânimo de formação de capital das empresas após o surto de investimento privado observado durante o segundo semestre de 2009 e o primeiro semestre de 2010”.

Para André Gunder Frank (1975), o desenvolvimento econômico e industrial no Brasil foi direcionado e limitado, nunca foi realmente autônomo, sendo assim, experimentamos o desenvolvimento do subdesenvolvimento:

\begin{abstract}
A expansão da economia mundial a partir do começo do século XVI converteu sucessivamente o Nordeste, o interior de Minas Gerais, o Norte e por último o Centro-Sul (Rio de Janeiro, São Paulo e Paraná) em economias de exportação e incorporou-as à estrutura e desenvolvimento do sistema capitalista mundial. Cada uma dessas regiões experimentou o que pode ter parecido um desenvolvimento econômico durante o período de suas respectivas idades de ouro. Mas se tratava de um desenvolvimento satelitizado, que não era nem autogerador nem auto-sustentável. E logo que o mercado ou a produtividade das três primeiras regiões declinou, o interesse econômico nessas regiões, tanto interno quanto externo, se desfez; e elas foram relegadas a desenvolver o subdesenvolvimento em que vivem hoje. (FRANK, 1973, p. 30).
\end{abstract}

Devemos esclarecer que André Gunder Frank não defendeu a idéia da impossibilidade de desenvolvimento genuíno nos países subdesenvolvidos, mas destacou que, enquanto persistisse o então contexto sócio-econômico por ele analisado, a relação com o capital externo se daria de forma subordinada onde a burguesia nacional seria o sócio menor do capital externo na acumulação capitalista.

Podemos notar hoje em dia os resultados do desenvolvimento do subdesenvolvimento brasileiro. De acordo com o documento divulgado pela ONU (2010) "O Estado das Cidades do Mundo 2010/2011: Unindo o Urbano Dividido", das vinte cidades mais desiguais do mundo, sete são brasileiras, sendo Belo Horizonte a segunda mais desigual do Brasil e a décima-terceira no mundo. A pesquisa vem de encontro com o 
que vemos em nosso cotidiano, o imenso abismo que separa os ricos dos pobres no Brasil. Obviamente, essa separação econômica se traduz em inúmeros outros tipos de disparidades que reproduzem ainda mais a desigualdade, como na oferta de serviços, na educação, no acesso à saúde, à cultura, etc.

A formação de uma desigualdade abismal como a brasileira, e também latinoamericana, encontra explicação, em parte, na inserção que temos na economia internacional. Somos basicamente produtores de commodities que beneficiam, principalmente, o setor externo. A mais-valia, mesmo que produzida aqui, é apropriada em sua maior parte pelo setor estrangeiro, numa gigantesca transferência de valores baseada numa troca extremamente desvantajosa para os países dependentes. A classe dominante brasileira se insere no processo de acumulação de maneira subalterna, enquanto a maioria da população se encontra marginalizada. Ainda hoje, grandes setores da sociedade brasileira sobrevivem pelo subemprego, trabalho informal, etc.

\section{Minério-Dependência}

Em 2010, a mineração teve um superávit (numa relação entre importações e exportações) de US\$27,6 bilhões - o minério de ferro correspondeu a 81,8\% deste valor sendo que o saldo da balança comercial brasileira foi de US\$ 20 bilhões positivos, o que evidencia a dependência nacional pelas exportações de minérios. (Fonte: IBRAM, Sistema de Informações e Análises da Economia Mineral Brasileira, 2010, Quinta edição). Assim, a exportação de minério de ferro é fundamental para se atingir o superávit primário na balança comercial.

Algo fundamental para a interpretação do contexto minerador da região, o qual queremos destacar aqui, diz respeito ao caráter da dependência. Os mecanismos e consequências econômicas da dependência já foram expostos no começo do texto. Porém, é de suma importância compreendermos que a dependência vai para além do âmbito econômico, e é exatamente aqui que torna-se necessário a análise sociológica. Essa relação de países e, principalmente, entre classes, têm efeitos sociais que são, aqui, o nosso objeto de análise. 
A dependência econômica do quadrilátero ferrífero mineiro em relação à atividade mineira-exportadora faz com que inúmeras localidades desta região sobrevivam, quase, exclusivamente da mineração. A cidade de Raposos é, hoje em dia, uma cidade dormitório, e sua população jovem busca emprego em outros municípios. A cidade se encontra em declínio econômico desde o fechamento da mina de Raposos em 1998. A especialização na mineração se mostra em longo prazo prejudicial, visto que a população local torna-se dependente dos poucos empregos criados por uma atividade que tem prazo de validade. Com a infra-estrutura da região o lucro no curto prazo é possível apenas para as mineradoras que, dessa forma, serão as únicas a terem intenção de investirem na região. Assim, a população local se vê envolta numa "minério-dependência" que têm implicações além de econômicas, também, sociais e culturais. Movimentos contra-hegemônicos encontram obstáculos difíceis de serem superados, além do que a população local imersa no desemprego e subemprego facilita a instalação das mineradoras, sendo um elemento chave na negociação das mineradoras com as entidades locais e movimentos sociais. $\mathrm{O}$ discurso do desenvolvimento abre a possibilidade ilusória da resolução dos problemas sociais da região, atividade que se traduz, efetivamente, em um pequeno número de empregos e divisas criadas. Os problemas causados pela mineração são naturalizados por uma dicotomia da dependência onde entram em comparação ônus versus bônus. Os prejuízos decorrentes da mineração são suportados em troca de pequenas concessões feitas pelas mineradoras. O trabalho nas minas, por mais árduo que seja, é sinônimo para a população local de atendimento das necessidades humanas básicas, e é exatamente essa consequência de curto prazo o principal trunfo para a manutenção da atividade mineira-exportadora. Podemos ainda identificar como ônus minerador: a contaminação, destruição e assoreamento de rios e reservatórios de água; as renúncias fiscais na água, energia e no imposto de circulação de mercadorias; os gastos com a criação e manutenção de infraestrutura de transportes (tanto em estradas como em minério-dutos e ferrovias); a construção e manutenção de represas de rejeitos; destruição de formas de produção tradicionais; a sobrecarga do sistema de saúde local; o aumento da violência urbana; os gastos com o crescimento populacional repentino; a instabilidade nos preços do minério de ferro no mercado internacional; a concentração de renda; a renúncia ao incentivo de outras atividades econômicas; os constantes "acidentes" de trabalho; a superexploração do 
trabalho (com efeitos drakonianos, como a silicose e mortes em ambiente de trabalho); a limitada oferta de postos de trabalho. Dessa forma, pretendemos demonstrar os efeitos sociais e econômicos da atividade mineradora na população local, questionando, assim, o atual paradigma do desenvolvimento.

Essa dependência de uma única empresa, ou atividade econômica, possibilita uma maior tolerância por parte da população frente aos prejuízos, não só ambientais, mas também sociais, como a superexploração do trabalho. Aqui se evidenciam os efeitos sociais da dependência para além de suas consequências econômicas.

\section{Mineração e superexploração do trabalho}

As classes altas dos países periféricos não realizam uma exploração do trabalho, mas uma superexploração do trabalho, visto que dividem os lucros com as classes estrangeiras. O locus de consumo está predominantemente localizado nos países centrais, possibilitando uma superexploração do trabalhador, já que não será ele o sujeito do consumo.

Isso tem vários efeitos sociais, como os salários baixos, falta de oportunidades de emprego, analfabetismo, subnutrição, repressão policial e violência. A sociedade civil local se torna dependente dos interesses das mineradoras. Este contexto explica o descaso das classes altas mineradoras para com os trabalhadores. A consequência mais evidente na região de Raposos é a da propagação da doença silicose entre os trabalhadores da mineração. A silicose é uma doença irreversível, decorrente da inalação da poeira da sílica. As partículas da sílica, instaladas no pulmão, endurecem e reduzem progressivamente a capacidade respiratória da vítima, desenvolvendo a tuberculose ou câncer de pulmão. Na maioria dos casos é contraída por meio das más condições de trabalho e falta de equipamento de proteção. Descrita pela população como “doença do pó”, está intimamente ligada à história da cidade. No brasão da cidade há um lenço roxo representando as viúvas dos trabalhadores que morreram de silicose. Esse é o caso da Anglo Gold Ashanti (antiga Mineração Morro Velho) em Nova Lima e Raposos. São no total 3077 ex-trabalhadores agonizantes que contraíram a doença e somadas 40 mortes (Estado de Minas: 22/03/2009). Segundo dados da OIT (Organização Internacional do Trabalho) Minas Gerais é o estado 
campeão em número de mortes por silicose no Brasil. São focos de silicose no estado os municípios de: Teófilo Otoni, Raposos, Belo Horizonte, Dores de Guanhães, Itaúna, Corinto, Nova Lima e São Tomé das Letras. Uma série de processos jurídicos estão sendo movidos pelos sindicatos dos trabalhadores contra as Mineradoras.

Nos países dependentes o mecanismo econômico básico deriva da relação exportação-importação: ainda que se obtenha no interior da economia, a mais-valia se realiza na esfera do mercado externo mediante a atividade da exportação, e se traduz em ingressos que se aplicam, em sua maior parte, em importações. $\mathrm{O}$ excedente invertido, então, sofre a ação direta de fatores externos à economia nacional. A Vale S. A. é uma empresa privada que tem em sua composição de capital uma maioria de acionistas brasileiros. Porém, isso não quer dizer que as divisas criadas pela empresa sejam direcionadas para o desenvolvimento autônomo brasileiro. Como sua produção é voltada, majoritariamente, para a exportação também seus interesses estão voltados para o exterior. Além do que, como empresa privada que é, a Vale S. A. funciona sob uma lógica rentista, sem ter como foco principal o investimento em setores da economia nacional, as divisas produzidas não são direcionadas para o combate à desigualdade social e na erradicação da miséria.

A mineração não combate a desigualdade social. A concentração regional de renda fica evidente quando sabemos que $80 \%$ da arrecadação com a Compensação Financeira pela Exploração de Recursos Minerais (Cfem) vai para 40 municípios dos 360 municípios mineradores do estado (Jornal "Estado de Minas": 25/04/2010).

O setor da mineração ocupa, hoje, 30\% do PIB de Minas Gerais. A mineração responde por cerca de $10 \%$ do PIB brasileiro, o que responde a $\mathrm{R} \$ 150$ bilhões por ano (GODEIRO, 2007). No entanto, a mineração é uma das atividades econômicas que menos criam empregos. De acordo com levantamento da Fundação João Pinheiro, em fevereiro de 2010 os empregos diretos da atividade mineradora correspondiam à apenas 1,9\% do total de empregos de Minas Gerais.

Em questão de tributos os benefícios ao município minerador são irrisórios. Segundo a Constituição brasileira, as mineradoras devem pagar royalties, que não são classificados como impostos, mas como compensação pelos danos sofridos. Na mineração existe o CFEM (Compensação Financeira pela Exploração de Recursos Minerais), 
descontado no lucro líquido das empresas, sendo 3\% para a bauxita, potássio e manganês; $2 \%$ para o minério de ferro, caulim, cobre, níquel e fertilizantes e 1\% ouro. Em 2005, a arrecadação de CFEM foi de $\mathrm{R} \$ 406.047 .604,00$ representando $1,3 \%$ do total, $\mathrm{R} \$ 31.467 .021 .146,00$. Este imposto é distribuído em 12\% para a União, 23\% para Estados e $65 \%$ para os municípios.

\section{Conclusão}

Vimos que a relação de dependência se aprofunda com a reprimarização da economia brasileira que tem como principal produto de exportação o minério de ferro. Sendo assim, as características sociais do subdesenvolvimento como a miséria, a pobreza e a desigualdade social persistem mesmo com a produção de grandes riquezas e, ainda, a acumulação de capital se faz em detrimento das condições de vida do proletariado. Os efeitos sociais dessa dependência são ainda mais extremos nas regiões mineradoras. A mineração reforça e aprofunda os traços sociais clássicos do subdesenvolvimento, como a concentração de renda, a miséria e o desemprego. Ela também aprofunda a dependência sócio-econômica da região por essa atividade econômica e pelo mercado consumidor externo. Fica-se extremamente dependente das oscilações dos preços dos minérios no mercado internacional, que seguem uma média, apesar das baixas e altas dos preços, o que incide diretamente no aumento ou queda da atividade mineradora, evidenciando mais uma vez seu desenvolvimento de fôlego curto tendo a perspectiva da exaustão das minas. $\mathrm{O}$ ônus minerador atinge diretamente as populações dessas regiões onde a falta de alternativas econômicas é evidente. A concentração de renda aumenta na medida em que expande-se a mineração na região com a pequena criação de empregos e apropriação pelas mineradoras e seus acionistas do gigantesco valor produzido na atividade. Essa atividade minérioexportadora não diminui a desigualdade social porque seu funcionamento é rentista direcionado para a satisfação do mercado externo e de seus acionistas, além do que a compensação para o município pela explotação do minério de ferro é irrisória se comparada aos gigantescos lucros das mineradoras. Os caminhos e o planejamento no Quadrilátero Ferrífero será definido em esferas políticas que não consideram as demandas do proletariados local, e sim as demandas de acionistas e dos importadores de minério de ferro. 
A expansão da mineração amplia e reproduz essa relação de subordinação, que é uma relação entre classes.

\section{Referencias Bibliográficas:}

ALTÍSSIMO S. P.; SANTI A.M.M. Participação Social no Processo de Licenciamento Ambiental Corretivo no Distrito de Itabira- CVRD. In Anais do II Seminário Nacional Movimentos Sociais, Participação e Democracia. 2007, Florianópolis: NPMS 2007.

BETTELHEIM, Charles. A Problemática do "Subdesenvolvimento". In: Subdesenvolvimento e Desenvolvimento. Luiz Pereira (org). Zahar: Rio de Janeiro, 1969.

BIELSCHOWSKY, Ricardo. Cinquenta anos de pensamento na CEPAL- uma resenha. In: Cinquenta anos de Pensamento na CEPAL. Ricardo Bielchowsky (org.). Rio de Janeiro: Record, 2000.

BRESSER-PEREIRA, Luiz Carlos. Do ISEB e do CEPAL à Teoria da Dependência. In: Caio Navarro de Toledo (org.) Intelectuais e Política no Brasil: A Experiência do ISEB. Rio de Janeiro: Editora Revan, 2005.

CARCANHOLO, Marcelo. Dependência e superexploração do trabalho no desenvolvimento periférico. In: SADER, Emir e SANTOS, Theotônio dos (coords.). A América Latina e os Desafios da Globalização: ensaios dedicados a Ruy Mauro Marini. Boitempo: São Paulo, 2009.

CARDOSO, Fernando Henrique e FALETTO, Enzo. Dependência e Desenvolvimento na América Latina. In: Cinquenta anos de Pensamento na CEPAL. Ricardo Bielschowsky (org.). Rio de Janeiro: Record, 2000.

FRANK, Andrew Gunder. Desenvolvimento e Subdesenvolvimento Latino-americano. In: Urbanização e Subdesenvolvimento. Luiz Pereira (org.). Zahar: Rio de Janeiro, 1973. 
FURTADO, Celso. A Formação Econômica do Brasil. Ed. Nacional e Publifolha: São Paulo, 2000.

FURTADO, Celso. Formação de capital e desenvolvimento econômico. In: A Economia do Subdesenvolvimento. Agarwala / Singh (orgs.). Cia Editora Forense: Rio de Janeiro, 1969.

GODEIRO, Nazareno (org.). Vale do Rio Doce. Nem tudo que reluz é ouro, da privatização à luta pela reestatização. Editora Sundermann: São Paulo, 2007.

GOMES, João Oliveira. Memórias do Povo de Raposos. Editora Lê: Belo Horizonte, 1996.

LOPES, José S. L. A Ambientalização dos Conflitos Sociais: Participação e Controle Público da Poluição Industrial. 2004, Relume Dumará, Rio de Janeiro.

MARCUSE, Herbert. Tolerância Repressiva. In: Crítica da Tolerância Pura. Ed. Zahar: Rio de janeiro, 1970.

MARINI, Ruy Mauro. Dialética da Dependência. In: Ruy Mauro Marini- Vida e Obra.

TRASPADINI, Roberta e STÉDILE, João P. Expressão Popular: São Paulo, 2005.

MARINI, Ruy Mauro. Subdesarrollo y revolución. Siglo XXI: México, 1985.

MINAYO, Maria Cecília de Souza. De Ferro e Flexíveis: marcas do Estado empresário e da privatização na subjetividade operária. Garamond: Rio de Janeiro, 2004.

MINISTÉRIO DO DESENVOLVIMENTO, INDÚSTRIA e COMÉRCIO EXTERIOR. Balança Comercial Brasileira: dados consolidados (2009). Disponível em $\langle$ http://www.mdic.gov.br/arquivos/dwnl_1275505327.pdf>. Data de acesso: 05/06/11.

O ESTADO das Cidades do Mundo 2010/2011: Unindo o Urbano Dividido. Relatório da ONU-HABITAT, 2010. 
SANTOS, Theotônio dos. Brasil: la Evolución Historica y la Crisis del Milagro Economico. Ed Nueva Imagen: México-DF, 1978.

SITE da Vale. Consultado no dia 26/07/2010.

PAULA, João Antônio. A formação do mercado interno e a superação do subdesenvolvimento em Celso Furtado. In: Celso Furtado e a Formação Econômica do Brasil. Rui Guilherme Granziera e Francisco da Silva Coelho (orgs.). Ed. Atlas, 2009.

PRADO Jr., Caio. Historia Econômica do Brasil. Ed. Brasiliense: São Paulo, 1984.

PRÉBISH, Raúl. Estudo Econômico da América Latina. In: Cinquenta anos de Pensamento na CEPAL. Ricardo Bielschowsky (org.). Rio de Janeiro: Record, 2000. 